\title{
Lung function assessed by home Forced Oscillation and self reported symptoms during COPD exacerbations
}

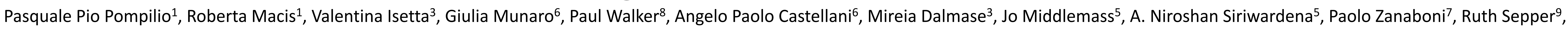
Kaiu Prikk ${ }^{9}$, Andrei Malinovschi ${ }^{4}$, Christer Janson ${ }^{4}$, Dorjan Marušič ${ }^{10}$, Tatjana Dolgan ${ }^{10}$, Raffaele L. Dellaca ${ }^{2}$, Peter M.A. Calverley ${ }^{8}$, Roberto Rosso ${ }^{6}$ on behalf of CHROMED consortium

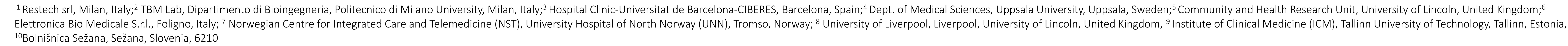

CHROMED is an EU-funded, multicenter, randomized trial aimed at evaluating the socio-economic impact of a home-monitoring platform on the quality of life of COPD patients with comorbidities.

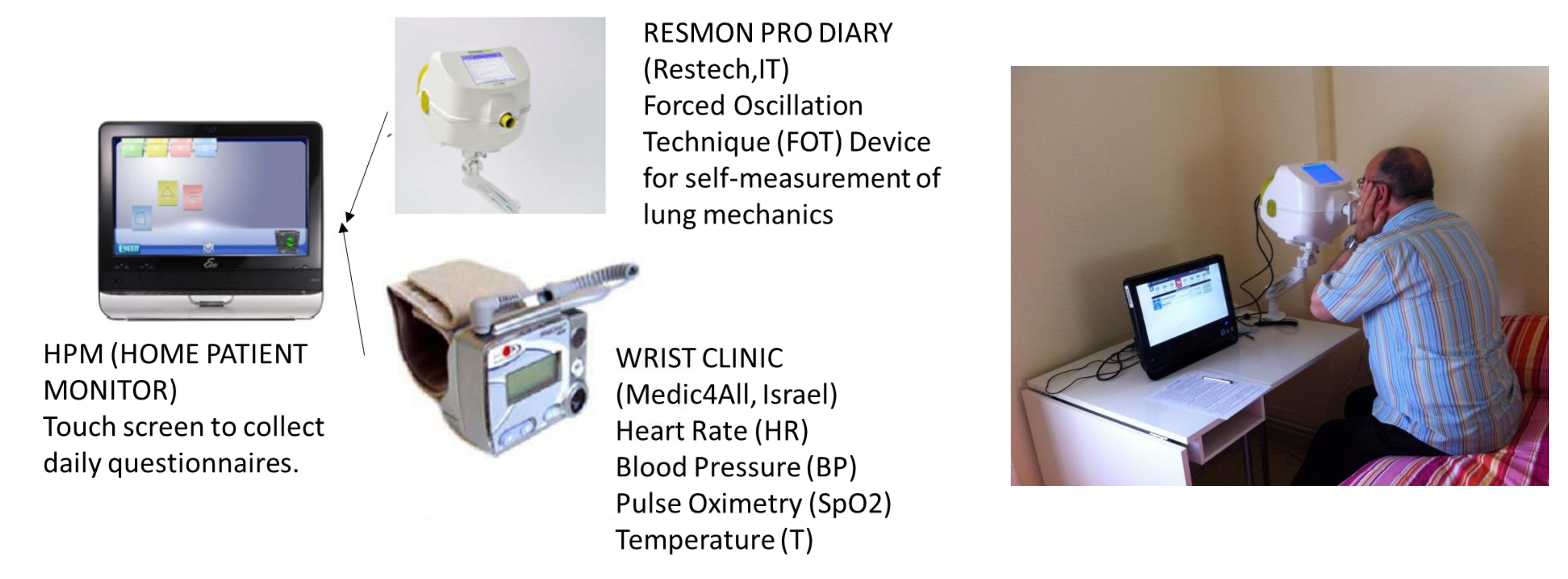

Fig.1: CHROMED home monitoring platform

- Population: Elderly (>65yrs) COPD patients (GOLD stage $\geq 2$ ), with at least one comorbidity and $\geq 1$ exacerbation in the previous year randomly assigned to an interventional or control group.

Protocol: For 9 months, monitored patients performed daily selfassessment of lung mechanics with a FOT (Forced Oscillation Technique) device and completed a symptom diary card (see Table 1). Any detected worsening in lung mechanics generated an alert triggering a phone interview directed at verifying the patient's status and optimizing treatment.

Table 1: Symptom diary card. Major symptom (M), minor symptom(m)

\begin{tabular}{|ll}
\hline $\begin{array}{c}\text { Please select any WORSENING of } \\
\text { symptoms ABOVE YOUR USUAL } \\
\text { daily level: }\end{array}$ & $\begin{array}{l}\text { No changes } \\
\text { increased BREATHLESSNESS (M) } \\
\text { increased SPUTUM COLOUR (M) } \\
\text { increased SPUTUM AMOUNT }(\mathrm{M}) \\
\text { increased COUGH }(\mathrm{m})\end{array}$ \\
increased WHEEZE or CHEST TIGHTNESS $(\mathrm{m})$
\end{tabular}

Partners of the consortium:

\begin{tabular}{|c|c|c|c|c|c|}
\hline RESESTECH & $\begin{array}{c}\text { RESTECHSRL } \\
\text { ITALY (RES) } \\
\end{array}$ & 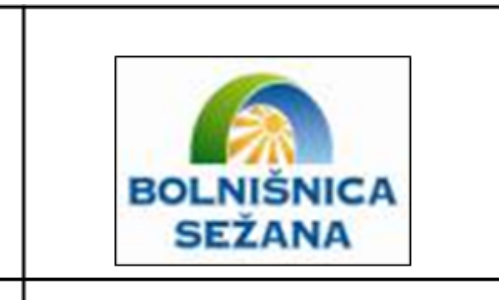 & $\begin{array}{l}\text { HOSPITALOF } \\
\text { SERANA } \\
\text { SLOVENAA (SHO) }\end{array}$ & (囚) & $\begin{array}{l}\text { BARCELNA } \\
\text { UNINESSTIVI } \\
\text { SPAIN(UB) }\end{array}$ \\
\hline 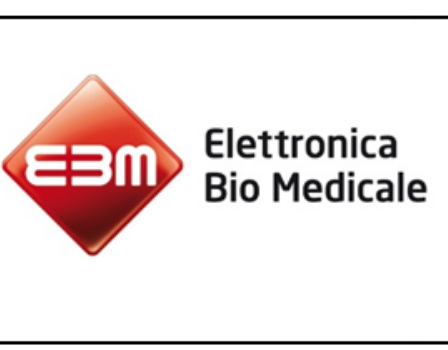 & 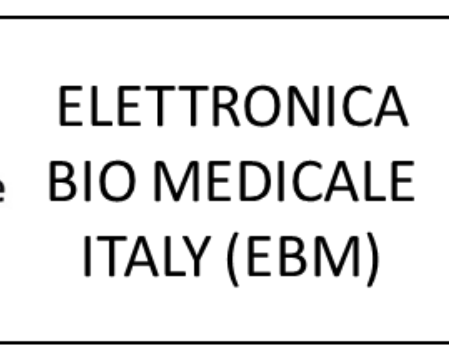 & T: & $\begin{array}{l}\text { UNIVESSIT OF } \\
\text { LIVERPOOL } \\
\text { UR (ULIV) }\end{array}$ & 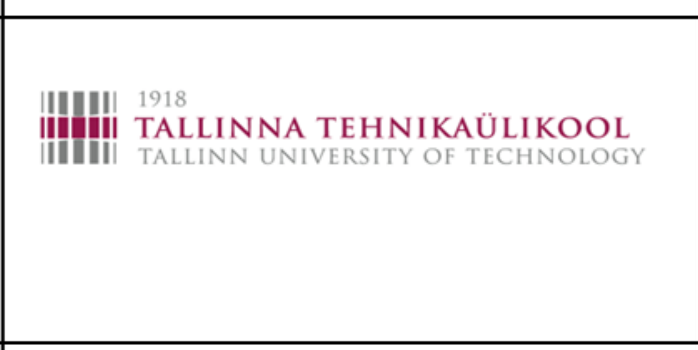 & 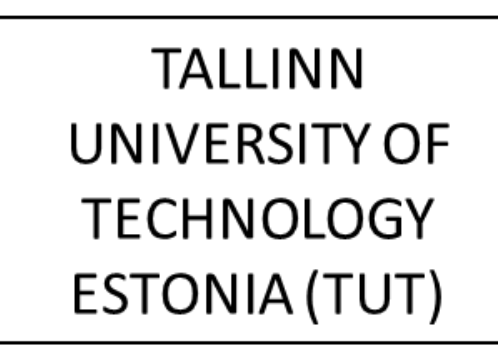 \\
\hline 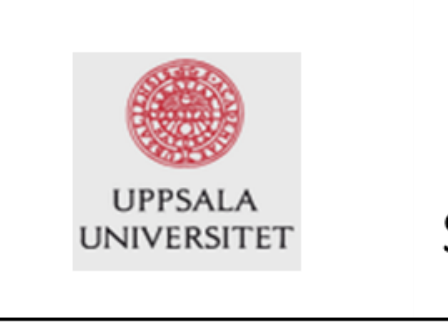 & $\begin{array}{l}\text { UNIVERSITY OF } \\
\text { UDPSALA } \\
\text { SWEDEN(LUPP) }\end{array}$ & 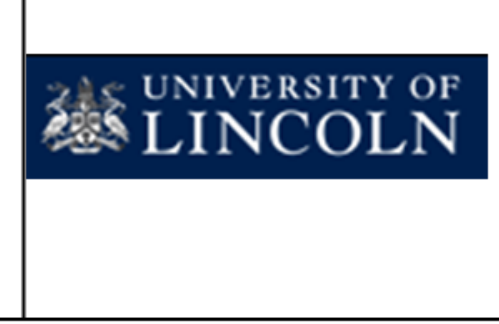 & $\begin{array}{l}\text { UNIVESITY OF } \\
\text { UNCON } \\
\text { UK (ULIN) }\end{array}$ & 2 & 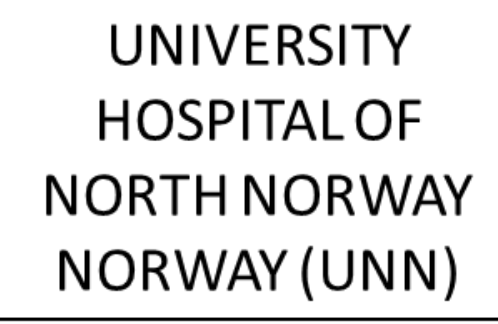 \\
\hline
\end{tabular}

\section{Methods}

- Data from 70 patients in the monitoring arm.

- Patient compliance: number of measures received/number of scheduled measures.

- A worsening event has been defined as a cluster of persistent alarms generated within 7 days.

- A symptom-based exacerbation was identified using diary cards if at least one major and one minor symptom were present for at least 2 consecutive days (Seemungal et al., Am J Respir Crit Care Med 1998). - Association between a worsening event, a prescribed treatment and the presence of a symptom-based exacerbation was investigated for the week preceding and the week after the date of generation of the first alarm.

\section{Results}

Population

$$
\begin{array}{l|l}
100 \% & \\
90 \% & \text { NONE: } 4 \% \\
80 \% & \text { - SDB: } 1 \% \\
70 \% & \\
60 \% & \text { CARDIOVASCULAR + } \\
50 \% & \text { SDB + OBESITY: } 4 \% \\
40 \% & \text { CARDIOVASCULAR + } \\
30 \% & \text { OBESITY: } 6 \% \\
20 \% & \text { CARDIOVASCULAR + } \\
10 \% & \text { SDB: 9\% } 9 \\
0 \% & \text { CARDIOVASCULAR: } \\
\hline \text { Fig. 2: Comorbidities distribution. } \\
\text { Cardiovascular diseases: Congestive heart } \\
\text { failure, hypertension, ischaemic disease, } \\
\text { hyperlipaedemia. SDB: Sleep disordered } \\
\text { breathing. }
\end{array}
$$

Table 1 - Baseline data Nr of patients (M/F) 57/13

Age $\quad 71,6 \pm 5,9$

$\operatorname{BMI}\left(\mathrm{Kg} / \mathrm{m}^{2}\right)$

Smoking history

(pack/years)

\%FEV1 postBd

\%FVC postBd

\%FEV1/FVC postBd

Exacerbations last yr

Hospitalizations

last yr

$27,4 \pm 5,2$

$42,8 \pm 25,5$

$47,8 \pm 15,5$

$72,0 \pm 19,0$

$67,8 \pm 18,3$

$2,1 \pm 1,2$

$1 \pm 0,9$

Patients' compliance

$0 \%$
OF

NR OF FOT DAILY
TESTS $40 \%$ $60 \%$ $80 \%$ $100 \%$

NR OF DAILY QUESTIONNAIRES 8601752
Worsening events

- 381 Alarms have been generated in the whole period resulting in 311 worsening events.

- Rate of worsening events per patient was $0,65 \pm 0,3$ per month.

- $48 \%$ of the CHROMED worsening events ${ }^{1}$ were associated with treatment and/or a symptom-based exacerbation. An additional $15 \%$ of events was associated with worsening of one major symptom. (see Fig.4)

$$
\begin{aligned}
& \text { Tre } \\
& \text { Un } \\
& \\
& \\
& \text { Fig4 } \\
& \text { asso } \\
& \text { 101 } \\
& \text { gener }
\end{aligned}
$$

generation

Eight (11\% of the population) patients generated $48 \%$ of the asymptomatic untreated worsening events.

\section{Conclusions}

- Patients'compliance to the study protocol was high, confirming the suitability of FOT as an unsupervised monitoring tool in a community setting.

- The majority of CHROMED events were associated with a treatment and/or a worsening in lung perceived symptoms.

$\square$ Received $\quad$ >48 hrs Later $\square$ Missing

Fig. 3: FOT measurements and completed questionnaires

- In a small group of patients, a worsening in lung mechanic was neither associated with a worsening in symptoms nor with a prescribed treatment. 